\title{
Praxis religiosa y contexto social: un método de análisis en "Historia Oral" e investigación cualitativa
}

\author{
Heinrich Schäfer \\ Seminario Bíblico Latinoamericano \\ San José, Costa Rica
}

En la frontera entre Nicaragua y Costa Rica aparece un costarricense con una carreta llena de arena para ir con ella a Nicaragua. El inspector de aduana nicaragüense lo controla. No tengo nada que declarar, dice el hombre. Lo dejan pasar. Pocos días más tarde aparece de nuevo con una carreta llena de arena. Controlan sus papeles con algo de desconfianza, y lo dejan pasar. Dos días después está de nuevo en la frontera. El inspector lo hace volcar la carreta, examina la arena y la carreta, no aparece nada. Lo deja pasar. Ahora el hombre aparece con regularidad y, con el tiempo, se desarrolla una amistad entre los dos. $\mathrm{Al}$ año el inspector le dice: "Mirá, yo sé que estás contrabandeando algo. Somos amigos, y no te voy a dilatar. Pero ¡dímelo!" "Bueno", dice el otro, "yo hago contrabando de carretas".

\section{El problema}

Bastante similar a lo que narra este chiste, sucede un contrabando cuando interpretamos datos históricos, sociales y religiosos. Tácitamente se transfieren los axiomas implícitos de nuestro pensamiento a los datos que interpretamos y a los resultados que obtenemos. Este problema es especialmente grave en la Historia Oral ya que los interlocutores son contemporáneos, pero es pertinente para toda investigación histórica.

Un ejemplo desde la Historia Oral: Mi esposa y yo, ella antropóloga y yo teólogo, estudiamos iglesias pentecostales y neopentecostales durante dos años en Guatemala y Nicaragua. Comenzamos en una aldea del altiplano guatemalteco, viviendo varios meses con una iglesia pentecostal de la Asambleas de Dios. El pastor y los miembros compartían la misma opinión: "Es que (...) en las Asambleas de Dios tienen un reglamento que es muy duro y muy celoso. (...) Si (los cristianos) quieren tener la salvación, pues que se sujeten." (Entr. 29, una mujer indígena) Esto no me parecía como la "libertad del evangelio", sino como una "ley que mata". Así que rápidamente llegué a diagnosticar un "legalismo grave". - Una interpretación errónea, como podremos constatar más adelante. 
El problema estaba en la transferencia de axiomas implícitos de mi pensamiento en el proceso de observación y evaluación. Estos axiomas eran contenidos básicos de la teología luterana, heredadas de mi formación teológica: la distinción entre "evangelio y ley". Esta distinción básica de mi observación se había transferido a los datos de mi investigación. Es una distinción que opera con contenidos teológicos los que permiten observar y clasificar la realidad social. Sólo que no encajaba con la realidad social de los grupos observados.

¿Cómo resolver este problema?' Cada observación necesita distinciones básicas (George Spencer Brown y, siguiendo, Niklas Luhmann). No podemos prescindir de ellas. Pero sí podemos hacer un giro que nos permite abordar objetos histórico-religiosos de otra manera. Proponemos aquí, por tanto, un método que trabaja a partir de una distinción básica que relaciona dos elementos fundamentales a tomar en cuenta al hablar de sistemas religiosos. No vamos a preguntar por "evangelio, ley, pneumatología, cristología, ni por liberación, opresión" etc., ni tampoco por "influencia de ideas políticas (liberales, conservadores etc.), afiliación política, función social" etc. Todos estos factores se pueden tratar con el método. Pero no juegan el papel de distinciones básicas de la observación. Como distinción básica de observación estableceremos más bien la relación entre el contexto social y la praxis religiosa.

Escogeremos dos muestras pequeñas y bien definidas para ejemplificar el trabajo con el modelo: pentecostales y neopentecostales en Guatemala hace 11 años (ver cap. 3). No vamos a disertar sobre los pentecostalismos en América Latina. ${ }^{2}$ Vamos a ejemplificar (!) un método de análisis que, como método (!), es válido para cualquier praxis religiosa. El valor heurístico de los dos ejemplos está en que se pone lo siguiente de relieve: el método puede filtrar a partir de un inventario religioso (simbólico y práctico) muy similar dos praxis religiosas muy diferentes a causa de diferentes contextos y, por lo tanto, uso distinto de los símbolos. Los contenidos que resultan del análisis valen para cada muestra

' El problema de la transferencia parece ser, a primera vista, el mismo que Hans-Georg Gadamer, Wahrheit und Methode. Grundzüge einer philosophischen Hermeneutik. Tübingen 1975, trata bajo el concepto de las preconcepciones. No lo es por completo, por razones que aquí no necesitan explicarse más a fondo.

2 Por la incidencia fuerte del positivismo, la osteoporosis del pensamiento científico, lamentablemente se impone la necesidad de una advertencia expressis verbis: este aporte cjemplifica en dos muestras un método. Quien lo quisiera criticar por no abordar a todas las formas que toma el pentecostalismo en América Latina o porque los resultados materiales del inńlisis de las dos muestras no encajan con todas las otras praxis pentecostales, muestra solamente la limitación positivista de su propio pensamiento. Si uno pide peras al olmo, pone de relieve que no tiene idea de botánica. 
específicamente. El valor heurístico del modelo está en la distinción, no en la generalización. Nos vamos a limitar, además, a problemas puramente de análisis de documentos. La teoría praxeológica que apoya el método, no obstante, da para mucho más. Permite un nuevo abordaje a problemas como el del "sincretismo", el de los actores sociales, el de las estructuras objetivas y el actuar del sujeto etc. todos ellos problemas relevantes para la historiografía.

\section{Teoría social}

No pudiendo tocar esos temas por razones de espacio, estas notas sobre la teoría social se limitan a lo imprescindible para poder solucionar nuestro problema hermenéutico, mencionado al principio. La investigación histórico-religiosa parte de un análisis sociológico de la praxis (bios [Aristoteles], incluyendo discursos) para evitar la presencia y los efectos de contenidos teológicos o políticos como guías de la observación. Trabajamos a partir de la distinción sociológica entre contexto social y praxis religiosa. Esta se inscribe en un modelo del habitus religioso.

Con el modelo del habitus nos remitimos a la teoría social de Pierre Bourdieu quien subraya dos factores importantes: primero que "los mismos conceptos y las mismas prácticas tienden a asumir sentidos opuestos cuando se usan a fin de expresar experiencias sociales radicalmente opuestas ${ }^{13}$. Segundo, que la "explicación de las prácticas y creencias religiosas por el interés religioso... nos puede dar cuenta... de las propias creencias (croyance)". ${ }^{4}$

Para nuestros fines entenderemos los discursos, el llamado "universo simbólico" no como una representación de la realidad. ${ }^{5}$ Más bien concebimos los signos

${ }^{3}$ Pierre Bourdieu, Genèse et structure du champ religieux, en: Revue française de sociologie, vol. XII, 1971, No.3, pág. 316.

${ }^{4}$ Ibíd.

${ }^{5}$ Hablaremos en un vocabulario que se orienta en la teoría social praxeológica del sociólogo francés Pierre Bourdieu. Nos basamos menos en sus trabajos sobre el campo religioso (Bourdieu: Genèse..., op. cit. y Une interprétation de la théorie de la religion selon Max Weber, en: Archives européennes de sociologie, vol. XII, 1971, no.1, págs. 3-21) que en los trabajos sobre la cultura en general (Bourdieu, Esquisse d'une Théorie de la Pratique, précédée de trois études d'etnologie kabyle, Genève 1972; La distinction. Critique sociale du jugement, Paris, 1979; Le sens pratique, Paris, 1980). Entendemos a la religión como un elemento de la praxis social. Esto no es algo nuevo. No obstante, creo que el vocabulario praxeológico tienc muchas ventajas sobre otros vocabularios sociológicos actuales. Por la orientación en la praxis se busca evitar las falacias de diversas herencias teóricas: el platonismo residual, los signos como representaciones de cosas, la conciencia como lugar de esa representación (o sea la teoría especular de la conciencia), la reducción individualista y racionalista del conceplo del sujeto, la reducción normativista del concepto del actor, la contraposición estéril cntre individuo y sociedad así como la yuxtaposición entre el axioma básico de producción (cl 
mismos (según Wittgenstein) como prácticas sociales, cuyo sentido se explica por su uso social. Los signos son elementos activos de una lógica práctica. Los sistemas de signos permiten operaciones prácticas y se ajustan a las condiciones sociales de tales operaciones. En este sentido, también la religión forma parte de las lógicas prácticas de determinados sectores sociales.

A partir de la socialización de individuos y grupos, así como según los diferentes campos de praxis, se forman disposiciones para percibir, clasificar, juzgar etc. las experiencias de una determinada manera, y para actuar correspondientemente. Se genera el "habitus". Las disposiciones del habitus no forman un sistema lógico conclusivo, pero permiten una coherencia relativa de la praxis. Encajan con la realidad social correspondiente y generan prácticas, tanto acostumbradas como nuevas. De este modo orientan y limitan la praxis social de los individuos y grupos. En el habitus se generan las disposiciones, se almacenan como estructuras habituadas y se transforman. Así, se podría hablar de una "red dinámica de transformaciones" (Maturana/Varela). ${ }^{6}$. Un modelo del hábitus debería de tomar en cuenta estos dos aspectos: el generativo y el estructural.

El habitus genera una coherencia relativa entre las disposiciones de percepción, de juicio y de acción. Las relaciona sin que las iguale completamente. Un modelo del habitus deberia de distinguir entre estas disposiciones.

Un habitus es incorporado. No se restringe solamente al nivel cognitivo, sino también incluye afecto y cuerpo. El habitus es hecho figura (Gestalt), estatura, complexión. Las disposiciones cognitivas corresponden muy de cerca a las afectivas y corporales. ${ }^{7}$ Nuestro modelo del habitus aqui no toma en cuenta las dimensiones afectiva y corporal. Nos limitamos al nivel cognitivo.

Además, un habitus nunca es simplemente individual ni simplemente colectivo. Se genera y se estructura durante los procesos de socialización, en las historias de vida individuales en las cuales se impregnan las posiciones sociales específicas con todo su bagaje de estilos, condiciones, limitaciones, posibilidades etc. El habitus es simultáneamente individual y colectivo. En un cierto campo de acción

esquema sujeto-objeto de Hegel y otros) y el de comunicación (Habermas y su escuela de la teoría crítica, el interaccionismo simbólico y otros). Asi que, por ello, los logros de esas corrientes queden sin atención.

${ }^{6}$ Der Baum der Erkenntnis, Bern 1987, en el contexto de los sistemas auto-poiéiticos.

${ }^{7}$ El lenguaje coloquial tiene una gran cantidad de expresiones "figurativas" para expresar esa correspondencia: "llevar la nariz alta", "arrastrarse a los pies de alguien", "rectitud", hacer algo a "regañadientes" etc. En vista de construir nuestro modelo aquí, este aspecto no tiene tanta importancia. Sí sería importante al analizar e interpretar secuencias rituales de un culto, p.e., o de un exorcismo. Nosotros enfocamos discursos al nivel cognitivo, y por lo tanto no tenemos que profundizar más sobre este aspecto. 
existen, por tanto, homologías y diferencias entre individuos y grupos, individuos e individuos y entre grupos y grupos, que se pueden concebir a partir de los habitus específicos. Nuestro modelo enfoca el habitus colectivo de diferences grupos y trata a las diferencias individuales como transformaciones o variantes de éste.

Si hablamos del habitus religioso, es por nuestro interés de investigación. No pensamos que existe algún objeto que se podría llamar habitus religioso apartc de otro que sería el habitus económico etc. Más bien concebimos el habitus religiosos de un cierto grupo como el modo incorporado de la lógica práctica de una posición determinada en el campo de la praxis religiosa. Y este campo se delimita por el interés de la observación; no es una entidad social "en sí". Nuestro modelo enfoca la praxis social desde el punto de vista de la religión. Todos los otros campos de acción son relevantes también en tanto que emergen como tales en la investigación.

Tratamos a la religión como una praxis social. Se dirige por las necesidades humanas - sobre todo por la necesidad de una coherencia relativa de la praxis. Por ello, la religión cobra relevancia especial frente a experiencias de crisis. Por su referencia meta-social, la religión permite interpretar y transformar las crisis. Construimos nuestro modelo, por tanto, a partir de experiencias sociales de crisis y de los elementos religiosos que interpretan estas experiencias.

\section{La red del habitus religioso}

En lo siguiente, demostraremos a base de dos ejemplos escogidos de nuestras investigaciones de campo en Guatemala, cómo fue posible evitar la transferencia de contenidos religiosos o políticos por la construcción de un modelo socioreligioso.

Construimos el modelo a partir de la relación entre contexto social y praxis religiosa. Ésta se especifica como la relación entre demanda y oferta de sentido.

Con el modelo trataremos de construir el habitus religioso de nuestros interlocutores. Como tal, nos servimos del modelo para construir las disposiciones cognitivas que permiten a los actores religiosos percibir, juzgar y actuar en sus contextos. Construiremos la estructura y las transformaciones de estas disposiciones.

\subsection{EI modelo formal (cuadro 1)}

En el cuadro 1 se puede apreciar la estructura básica del modelo, el así llamado "cuadrado lógico". Se remite a la lógica medieval y ha sido usado por Algirclas J. Greimas para analizar las estructuras profundas del sentido en textos. Con los 
debidos cambios se puede transformar para el análisis sociológico y usarse como estructura básica de toda una red de relaciones.

Aquí sólo un breve comentario: El modelo consiste de cuatro posiciones ( $\underline{A}, A$, B y $B$ ). A éstas se adjudican diferentes significados y diferentes relaciones lógicas entre sí:

- Experiencia social de crisis $(\underline{A})$, como entrada de la demanda de sentido en el modelo y como punto de partida de la construcción del modelo;

- elemento religioso central (A), como pivote para la oferta simbólicoreligiosa; este elemento contradice religiosamente a la experiencia de crisis y la interpreta;

- la posición religiosa de los adeptos $(\underline{B})$, como posición que éstos se auto-adjudican; se deriva de la orientación religiosa y es contraria a las experiencias de crisis;

- la razón religiosa de la crisis (B), tal y como se percibe desde la posición de los adeptos.

Entre estas posiciones hay un proceso constante de transformación lógica que procede desde la experiencia social, por el elemento religioso central y la posición de los adeptos hacia la razón de la crisis para regresar, finalmente, a las experiencias de crisis.

En lo siguiente damos solamente dos ejemplos de nuestro estudio de campo. Se basan en el análisis de 20 entrevistas cada uno.

\subsection{Las Agrupaciones Establecidas Pentecostales (cuadro 2)}

Así denomino iglesias como las Asambleas de Dios: establecidas, con formación relativamente fuerte de jerarquías, teniendo frecuentemente relaciones con centrales misioneras en los EE.UU., membresía primordialmente de la clase baja, algunos de clase media baja. En tiempos de rápido decaimiento económico y guerra contrainsurreccional, las personas entrevistadas vivían un descenso lento, pero seguro, hacia la pobreza extrema, la muerte de sus niños mal nutridos, la violencia militar omnipresente y una imposibilidad completa de hacer algo para el cambio político y social. Se veían a sí mismos como víctimas de una realidad sin explicación, e incapaces de cada acción liberadora o transformadora de esta realidad. Esta experiencia se condensó muy frecuentemente en la exclamación de que "iya no hay para dónde!" ( $\underline{A})$ - expresión de una pérdida de futuro en términos de perder perspectivas viables de acción. A esta situación se le contrapone, en el habitus religioso, el pronto "rapto de la iglesia" (A) al cielo. Nota bene: el elemento central es escatológico, y no pneumatológico, como se suele pensar de iglesias pentecostales. El "rapto" implica, ahora, la posición de los 
creyentes (B) como "preparación (al rapto)". Los creyentes se entienden como parte de una iglesia que se prepara para ir al cielo. Correspondientemente, las experiencias de crisis se interpretan como "signos de los últimos tiempos" (B). la distinción semántica básica de este discurso es la de "sucesos históricos versus sucesos no-históricos". Quiere decir: justamente el hecho de que la iglesia se constituye a partir de procesos meta-históricos - lejos de cada posibilidad de influencia por parte de los seres humanos - este hecho hace posible que los creyentes puedan seguir existiendo en sus condiciones históricas; y que puedan seguir existiendo con dignidad. Esto corresponde a la lógica práctica de muchas personas que no tenían la posibilidad de acción relevante en los conflictos sociales, pero querían sobrevivir con dignidad.

\subsection{Las Agrupaciones Establecidas Neo-Pentecostales (cuadro 3)}

Aquí me refiero a iglesias como Elim, Shekinah, El Shaddai, El Verbo etc. en Guatemala. Cada país tiene sus propias iglesias de este tipo, por razones que aquí no se pueden especificar. P.e. en Brasil, contaríamos la Igreja Universal do Reino de Deus a esta categoría, siempre mutatis mutandis. Se trata, en su mayoría, de iglesias relativamente establecidas con una fuerte jerarquía (centrada en uno o varios líderes carismáticos), autóctonas en términos financieros, siendo que la mayoría de la membresía forma parte de la clase media y media alta modernizadora. Estos interlocutores percebían la crisis económica y el conflicto militar como un ataque a su ascenso social, emprendido en los sesenta y tomado como incontenible. El problema central para estas personas era cómo se puede abolir esa "amenaza a su poder social" (스). A esta amenaza se contesta con el "poder del Espíritu Santo" (A). Este poder implica que los creyentes se constituyeran - individualmente - como "cristianos con poder" (B) . Como razón de la amenaza se determina la "acción de demonios" (B) en diferentes actores sociales (p.e. en la guerrilla, los sindicatos, los indígenas, la jerarquía católica etc.) o constelaciones psicosociales (p.e. en el "demonio del alcohol", de la infidelidad etc.). La distinción semántica básica de este discurso es "garantía de poder vs. lucha por el poder" - un problema de índole político, sobre todo. El poder del Espíritu Santo puede jugar un papel importante, fortaleciendo mediantc la experiencia religiosa y la organización social y política ${ }^{8}$ la posición social de los creyentes neopentecostales. Esta lógica práctica corresponde muy

\footnotetext{
${ }^{8}$ Estas iglesias, a diferencia de la otra muestra analizada, incentivan sus miembros para actuar en la política y hasta generan candidatos presidenciales y presidentes (como Serrano E.).
} 
íntimamente a las amenazas y las posibilidades de acción que vivía la clase media alta guatemalteca a mediados de los años ochenta.

\subsection{Comparación}

Sería interesante profundizar ahora en un análisis comparativo de los dos habitus religiosos. Pero tenemos que limitarnos a pocas palabras.

Lo más importante en términos heurísticos nos parece el siguiente hecho. A base de un inventario casi idéntico de símbolos y prácticas religiosos, se desarrollan dos habitus religiosos muy diferentes: uno fundado en la escatología enfatizando la perseverancia, y con tendencia escapista; el otro basado en la pneumatología, dado a la lucha social en términos de exorcismo. A base del contexto social y el uso de símbolos y prácticas religiosos, el método ha podido exponer claramente la distinción central entre dos formas de praxis religiosa que por lo general se tratan como similares hasta idénticas.

\subsection{La red de las disposiciones (cuadro 4)}

Claro que un habitus religioso no se describe con un simple cuadrado. Pero el cuadrado sirve como estructura básica para la construcción de una red amplia, inconclusa y abierta. Ésta permite diferenciar más el modelo del habitus a base de un análisis más detallado de los textos.

El cuadro 4 muestra tal modelo del habitus de los pentecostales establecidos. El centro (negrilla) es el cuadrado que hemos visto anteriormente (cuadro 2). La red es abierta (o sea: no tiene "dobladillo"), comprende contradicciones y posiciones vacías. Esto corresponde a la inconclusividad de la lógica práctica, o sea a su capacidad de adaptación y transformación.

La red también permite ver homologías, entre muchísimas otras p.e. las siguientes:

- "El rapto" implica "preparación" corresponde a "la iglesia como refugio" implica "esperanza a pesar de problemas".

- "Santidad" implica "solidaridad" corresponde a "Dios" implica "ayuda milagrosa".

De este modo, la red permite la construcción e interpretación de las disposiciones cognitivas del habitus religioso a partir de la demanda religiosa de los interlocutores y según la lógica práctica que se desdobla en su discurso.

\section{Conclusiones}

Déjennos terminar regresando a las preguntas iniciales: el legalismo y el contrabando. 


\subsection{Contenidos religiosos en la observación}

Un campesino indígena subraya lo siguiente: "La segunda venida del Sìnur, li estamos esperando también. Pero depende, si uno está bien limpio de conırou, silı mancha, sin arruga, se va. Si uno queda, uno tiene que sufrir la tribulación." (IıII 6, GD13) Este arminianismo ${ }^{9}$ práctico, sin embargo, ahora ya no lo interpretumu... como "legalismo". Más bien vemos que esa persona vive en una situación (jw $1 \ldots$ le permite ninguna acción más o menos exitosa en "el mundo"; vive fralciso tril: fracaso y sufre de una profunda destrucción de su auto-estima. "Ocuparse cke s11 salvación con temor y temblor" (Fil 2:12) significa aquí: tener la posibilidid de hacer siquiera algo. Y esto no es algo inútil para él, sino lo más importante qu uno puede hacer en estos tiempos finales: prepararse para el rapto, construir la comunidad del remanente santo y perseverar en bondad y equidad entre sí. La doctrina de la justificación inversa en un mundo al revés genera, de este modo, la libertad cristiana. En un mundo lleno de violencia y miseria, estos creyentes se repliegan a su iglesia, a la decencia individual y a las relaciones sociales más reducidas; y justamente por esto abren un campo para que sobreviva con dignidad una actitud profundamente humana -y que sobrevivan los seres humanos correspondientes también. Otro campesino indígena decía en un sermón: "Sabemos que todo trabajo que hacemos para la gloria del Señor no es en vano. Y si sabemos eso, no tenemos porqué afligirnos. Hermano, si Ud. tiene un problema, acuda al Señor y persevera. El Señor va a ver su pobreza, su sufrimiento, su pobreza." (Ser 8, GD10)

Sería interesante comparar ahora el habitus neopentecostal ${ }^{10}$ y referirnos a la dimensión afectiva y corporal ${ }^{11}$ también. Pero para ello nos falta el tiempo.

${ }^{9}$ Esta opinión no queda muy lejos del artículo 5 de la así llamada "Remonstrantie" (1610), cn la cual los Arminianos holandeses contraponen la necesidad de la "perseverantia" a la doctrinil calvinista de la predestinación eterna.

${ }^{10}$ Ahora, sólo rápidamente en nota a pie, la opinión de los interlocutores neopentecostales de clase media alta. Estos actores disponen de una buena basis económica y de perspectivas de acción social efectiva, si bien han llegado a encontrarse en una situación de defensa. En lá rc(l de sus disposiciones cognitivas, el énfasis en el Espíritu Santo como fuente de poder, en los carismas, en la expulsión de demonios etc. se combina con una certeza inamovible de ser gratuitamente salvos: "Creemos en la seguridad de la salvación eterna. Y creemos en li soberanía de Dios, absolutamente." (Int 58, GY2) A esto corresponde un énfasis en cl concepto de los carismas como dones gratuitos que habilitan para la lucha contri lo: demonios a todos los niveles. Y corresponde también la doctrina de que la fe cilısi prosperidad económica. Justificación es legitimar a una posición de un relativo poder sociul y a que ésta se fortalezca más...

"Hasta ahora sólo hablamos de la red cognitiva. Habría que hablar de las otras tambićn, Su podía observar p.e. una somatización de sus problemas tanto en los pentecostales como (I lin neopentecostales. En estos últimos p.e. se podía observar que la pérdida de control solure li 


\subsection{Las transferencias ilegítimas y el modelo}

El modelo es útil para no caer en la trampa de transferir contenidos teológicos. No obstante es necesario cuidarse de no caer en la otra trampa de transferir el modelo mismo.

El modelo no es la lógica práctica de los interlocutores, y ni es una imagen de esta. Por ello, los científicos no estamos sentados en "la posición del dios leibniziano" - como lo dijera Bourdieu. Si el modelo es bueno, podría a lo máximo "encajar" (Glasersfeld) bien con la praxis de los interlocutores. Esto tiene muchas implicaciones ${ }^{12}$ de las cuales sólo voy a mencionar una aquí.

El modelo nos permite entrar en diálogos. Esto lo experimento en mi propio trabajo con estudiantes pentecostales. Entrar en un diálogo a base del modelo expuesto aquí, significa básicamente lo siguiente:

- escuchar y hablar así que los interlocutores se sienten comprendidos;

- trabajar junto con los interlocutores en la solución de problemas que ellos tengan;

- exponer el modelo y el investigador mismo a la crítica por los interlocutores.

Para recordar, por último, la cuestión del evangelio y la ley: el uso "maiéutico" del modelo puede resultar de este modo en situaciones críticas. Cuando yo trabajé a base de este modelo con estudiantes teológicos de una iglesia pentecostal pobre, uno de estos pastores me preguntó: "Si es así como hemos visto ahora con este modelo ¿no podría ser que la doctrina de la 'justificación sólo por gracia' en Europa sirve nada más para abaratar la gracia y justificar la buena vida?"

sociedad y las posibilidades de consumo caminaba con una pérdida del control sobre la incorporación de alimentos, o sea con bulimia. Para comprender mejor a estos fenómenos, la combinación de las redes cognitiva, afectiva y corporal en el modelo podria ser útil.

${ }_{12}$ Tiene consecuencias, p.e., para la presentación de las descripciones. Se debería de contrastar el modelo y los textos analíticos siempre con materiales de la investigación tales como textos narrativos, obras de arte, símbolos religiosos, cantos, fotografías etc. Así se produce en los mismos lectores un excedente de sentido, no comensurable con el modelo analítico. De este modo, siempre queda consciente que la descripción científica no es una imagen de la realidad. El modelo siempre estará reconocible como un medio reductivo. Pero como tal, sí puede ser útil en el sentido de una guía en medio de la complejidad de testimonios de una realidad extraña. 
Modelo de transformación

Estructura básica

$\mathrm{S}$

A

Dimensión

simbólica
Dimensión

práctica

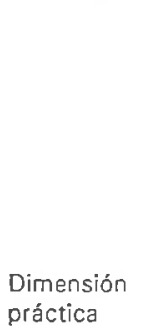

\section{Elemento religioso central}

$$
\begin{aligned}
& < \\
& < \\
& < \\
& < \\
& < \\
& < \\
& < \\
& < \\
& <
\end{aligned}
$$$$
\text { Posición religiosa }
$$$$
\text { de los adeptos }
$$

B
Razón religiosa de la experiencia

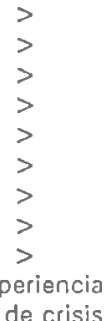
social de crisis

Procesos transformativos:

- $\quad<<<=$ Transformación epistémica

- $\quad>>>=$ Transformación práctica

Estructuras lógicas:

- Contradicción entre posiciones A y $\underline{A}, \mathrm{~B}$ y $\underline{B}$

- Implicación entre posiciones $A$ y $\underline{B}, B$ y

- Contrariedad entre posiciones A y B, $\underline{B}$ y $\underline{A}$

Ejes semánticos:

- $\quad \mathrm{S}=$ Sentido simbólico

- $\quad \underline{S}=$ Sentido práctico 
Cuadro 2

\section{Agrupación establecida pentecostal \\ Modelo de transformación}

\section{$S=$ sucesos no-históricos}

\section{A}

Dimensión

simbólica

Dimensión

práctica

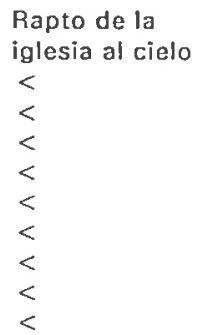

Preparación al rapto

$\underline{B}$

$$
\underline{\mathbf{S}}=\text { Sucesos históricos }
$$

B

signos de los ültimos tiempos

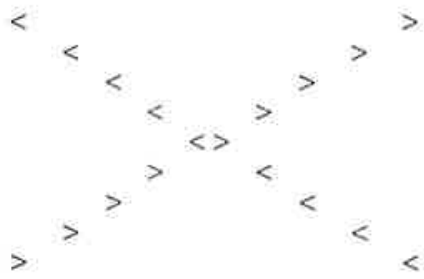

$>$
$>$
$>$
$>$
$>$
$>$
$>$

Pérdida de futuro

Procesos transformativos:

- $\quad<<<=$ Transformación epistémica

- $\quad>>>=$ Transformación práctica

Estructuras lógicas:

- Contradicción entre posiciones $A$ y $\underline{A}, B$ y $\underline{B}$

- Implicación entre posiciones A y $\underline{B}, B$ y $A$

- Contrariedad entre posiciones $A$ y $B, \underline{B}$ y $\underline{A}$

Ejes semánticos:

- $\quad \mathrm{S}=$ Sentido simbólico

- $\underline{\mathrm{S}}=$ Sentido práctico 


\section{Agrupaciọn establecida neo-pentecostal \\ Modelo de transformación}

$$
\mathbf{S}=\text { Garantía del poder }
$$

\section{A}

Dimensión

simbólica

Dimensión

práctica
Poder del

Espiritu Santo

$<$

$<$

$<$

$<$

$<$

$<$

$<$

$<$

$<$

Adeptos con poder

$\underline{B}$
Acción de los demonios

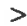

$>$

$>$

$>$

$>$

$>$

$>$

$>$

$>$

Amenaza al poder social de los adeptos

$\underline{\mathbf{S}}=$ Lucha por el poder

Procesos transformativos:

- $\quad<<<=$ Transformación epistémica

- $\quad>>>=$ Transformación práctica

Estructuras lógicas:

- Contradicción entre posiciones $A$ y $A, B$ y $B$

- Implicación entre posiciones $\mathrm{A}$ y $\mathrm{B}, \mathrm{B}$ y $\mathrm{A}$

- Contrariedad entre posiciones $A$ y B, $\underline{B}$ y $\underline{A}$

Ejes semánticos:

- $\quad S=$ Sentido simbólico

- $\quad \underline{S}=$ Sentido práctico 
Cuadro 4

Red de las disposiciones cognitivas

Agrupación establecida pentecostal

\begin{tabular}{|c|c|c|c|c|c|c|c|c|c|c|c|c|c|c|c|}
\hline & & & & & & & Infierno & -- & Cielo & - & Infierno & & & & \\
\hline \multirow[t]{2}{*}{$x$} & & $x$ & & $x$ & & $x$ & & $x$ & & $x$ & & \multirow{2}{*}{\multicolumn{2}{|c|}{$x$}} & \multirow{2}{*}{\multicolumn{2}{|c|}{$x$}} \\
\hline & & & & & & & $\begin{array}{c}\text { Salán } \\
\text { derrolado }\end{array}$ & - & $\begin{array}{c}\text { Dıós } \\
\text { vietorioso }\end{array}$ & - & Anticristo & & & & \\
\hline \multirow[t]{4}{*}{$x$} & 1 & $x$ & $b$ & $x$ & 1 & $x$ & 1 & $x$ & $\downarrow$ & $x$ & $\iota$ & \multirow[t]{2}{*}{$\times$} & \multirow[t]{2}{*}{+} & \multirow{2}{*}{\multicolumn{2}{|c|}{$x$}} \\
\hline & & & & & & & $\begin{array}{l}\text { Satónicos } \\
\text { derrotados }\end{array}$ & & $\begin{array}{l}\text { Viciona de } \\
\text { eristianos }\end{array}$ & - & $\begin{array}{l}\text { Suffımiento } \\
\text { an la Lierra }\end{array}$ & & & & \\
\hline & - & & - & & - & & - & & $=$ & & - & & - & & - \\
\hline & & & $\begin{array}{l}\text { Buscar ol } \\
\text { Evangelio }\end{array}$ & & [Dıds] & & $\begin{array}{l}\text { Proparar } \\
\text { la guerra }\end{array}$ & & $\begin{array}{l}\text { Boda del } \\
\text { cordero }\end{array}$ & - & Tribulación & - & Recompensa & & \\
\hline \multirow[t]{3}{*}{$x$} & 1 & $x$ & $\uparrow$ & $\times$ & $\uparrow$ & $x$ & 1 & $x$ & 1 & $x$ & 1 & $x$ & 1 & $x$ & \\
\hline & & & & & & & Antieristo & -5 & $\begin{array}{l}\text { Segunda venida } \\
\text { de Cristo }\end{array}$ & - & $\begin{array}{l}\text { Fin del } \\
\text { mundo cerca }\end{array}$ & - Is & $\begin{array}{l}\text { Segunda venida } \\
\text { de Cristo] }\end{array}$ & - & $\begin{array}{l}\text { Catástrofe } \\
\text { linal }\end{array}$ \\
\hline & $=$ & & - & & - & & $=$ & & $=$ & & - & & $=$ & & $=$ \\
\hline \multicolumn{2}{|r|}{ Guatamala } & - & Cuba & & Dios & & Diablo & & $\begin{array}{l}\text { Rapto do } \\
\text { la iglosia }\end{array}$ & \multicolumn{2}{|c|}{$\begin{array}{l}\text { - Signos de los } \\
\text { ûitimos tiempos }\end{array}$} & - & $\begin{array}{l}\text { Rofugio para } \\
\text { la Iglesia }\end{array}$ & - & $\begin{array}{l}\text { Acciones } \\
\text { del diablo }\end{array}$ \\
\hline \multirow[t]{3}{*}{$x$} & $t$ & $x$ & + & $x$ & $b$ & $x$ & 1 & $x$ & 1 & $x$ & 1 & $x$ & 1 & $\times$ & \\
\hline & $\begin{array}{l}\text { Liberad } \\
\text { raligiosa }\end{array}$ & - & $\begin{array}{l}\text { No libertad } \\
\text { religiosa }\end{array}$ & - & $\begin{array}{l}\text { Ayuda } \\
\text { milagrasa }\end{array}$ & $-{ }^{P}$ & $\begin{array}{l}\text { Permanencia de } \\
\text { problemas }\end{array}$ & & $\begin{array}{c}\text { Preparación } \\
\text { al rapro }\end{array}$ & - & $\begin{array}{l}\text { Pórdida } \\
\text { de futura }\end{array}$ & - & $\begin{array}{l}\text { Esperanza a p } \\
\text { da problemas }\end{array}$ & - & $\begin{array}{l}\text { Problemas } \\
\text { sociales }\end{array}$ \\
\hline & $=$ & & $=$ & & - & & 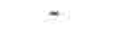 & & - & & - & & - & & - \\
\hline \multicolumn{2}{|c|}{$\begin{array}{c}\text { Ayudar a } \\
\text { no-cristianos }\end{array}$} & - & $\begin{array}{l}\text { [Problemas de } \\
\text { no-cris tuanos| }\end{array}$ & - & $\begin{array}{l}\text { Solidaridad } \\
\text { on congregac. }\end{array}$ & - & $\begin{array}{l}\text { Pecado contra } \\
\text { congragación }\end{array}$ & & Obediencia & - & $\begin{array}{l}\text { Pecar como } \\
\text { antes }\end{array}$ & - & $\begin{array}{l}\text { Testimonio } \\
\text { por oración }\end{array}$ & - & $\begin{array}{l}\text { Problemas } \\
\text { sociales }\end{array}$ \\
\hline$x$ & $t$ & $x$ & $t$ & $x$ & $\uparrow$ & $x$ & 1 & $x$ & $\dagger$ & $x$ & 1 & $x$ & $\uparrow$ & \multicolumn{2}{|l|}{$x$} \\
\hline \multicolumn{2}{|r|}{ [Cristianos] } & - & $\begin{array}{l}\text { [No- } \\
\text { cristianos] }\end{array}$ & - & Santudad & - & $\begin{array}{l}\text { Cristianos } \\
\text { "de nombre" }\end{array}$ & - & $\begin{array}{l}\text { Autoridad } \\
\text { eclesial }\end{array}$ & - & $\begin{array}{l}\text { Poder del } \\
\text { pecado }\end{array}$ & - & $\begin{array}{l}\text { Perdón } \\
\text { por Jesús }\end{array}$ & \multirow[t]{2}{*}{-} & $\begin{array}{l}\text { Maldad } \\
\text { humana }\end{array}$ \\
\hline & - & & - & & - & & - & & - & & - & & - & & - \\
\hline \multirow{3}{*}{\multicolumn{2}{|c|}{$x$}} & \multirow{3}{*}{$x$} & \multirow{3}{*}{+} & & $\begin{array}{l}\text { Oficios an } \\
\text { congragación }\end{array}$ & - & $\begin{array}{l}\text { Iglesió } \\
\text { falsa }\end{array}$ & - & $\begin{array}{c}\text { Iglesia } \\
\text { verdadera }\end{array}$ & - & Incrídulos & - & Cristianos & \multirow{3}{*}{$x$} & \multirow{3}{*}{$\downarrow$} \\
\hline & & & & $x$ & $b$ & $x$ & $\downarrow$ & $x$ & $\downarrow$ & $x$ & $\downarrow$ & $x$ & 1 & & \\
\hline & & & & & $\begin{array}{l}\text { Prestigio } \\
\text { en iglesia }\end{array}$ & - & $\begin{array}{c}\text { Ser } \\
\text { mundano }\end{array}$ & - & $\begin{array}{c}\text { Ser apartado } \\
\text { de falsos }\end{array}$ & - & Vicios & - & $\begin{array}{l}\text { Ser apartado } \\
\text { del mundo }\end{array}$ & & \\
\hline
\end{tabular}

Estructura central (negrilla): rapto - últimos tiempos $\times$ preparación - pérdida de futuro Signos utilizados:
$x$
= dos contradicciones (cruzadas);
$\uparrow \mathrm{y} \downarrow=$ implicaciones; $-=$ contrariedad;
$=$ equivalencia. 


\section{Resumen}

Según el tema del simposium, este aporte enfoca un problema de mírulu: wiv la transferencia de "preconceptos" sobre los datos en los procesos de inverslikn ción. A partir de la observación que observación sin distinciones básicus (Sipencel Brown/Luhmann) no es posible, se construye un modelo interpretativo pun controlar estas distinciones. El modelo trata la religión como una forma de pruxis social e interpreta las prácticas y discursos religiosos a partir de su contex(1) de uso (Wittgenstein). De este modo, la construcción se concibe como un modelo (lel habitus (Bourdieu) religioso. El aporte ejemplifica el modelo y su capacidad interpretativa en dos muestras determinadas del pentecostalismo y neopentecostalismo en Guatemala. 
Hans-Jürgen Prien (ed.)

\section{Religiosidad e Historiografía}

La irrupción del pluralismo religioso en América Latina y su elaboración metódica en la historiografía

Vervuert - Iberoamericana - 1998 
Impreso con ayuda de la Universidad de Colonia y del Verein der Freunde und Förderer der Universität Köln

Die Deutsche Bibliothek - CIP-Einheitsaufnahme

Religiosidad e historiografía : la irrupción del pluralismo religioso en América Latina y su elaboración metódica en la historiografía ; [actas del Simposio Internacional: "Religiosidad e Historiografía: la Irrupción del Pluralismo Religioso en América Latina y Su Elaboración Metódica en la Historiografía" del 15 al 16 de noviembre en el Instituto de Historia Ibérica y Latinoamericana de la Universidad de Colonia] / Hans-Jürgen Prien (ed.). - Frankfurt am Main : Vervuert ; Madrid : Iberoamericana, 1998 (Acta Coloniensia ; Vol. 1) ISBN 3-89354-191-8 (Vervuert) ISBN 84-88906-95-1 (Iberoamericana)

(c) Vervuert Verlag, Frankfurt am Main 1998

(C) Iberoamericana, Madrid 1998

Reservados todos los derechos

Diseño de la portada: Michael Ackermann

Impreso en Alemania 